\title{
An Empirical Method for Prediction of Cheese Yield ${ }^{1}$
}

\author{
C. Melilli*, J. M. Lynch†, S. Carpino*, D. M. Barbano†, G. Licitra*, and A. Cappał \\ ${ }^{*}$ Consorzio Ricerca Filiera Lattiero-Casearia, \\ Ragusa, Italy \\ †Northeast Dairy Food Research Center, \\ Department of Food Science, \\ Cornell University, Ithaca, NY 14853 \\ $\ddagger$ Associazione Provinciale Allevatori, \\ Vicenza, Italy
}

\section{ABSTRACT}

Theoretical cheese yield can be estimated from the milk fat and casein or protein content of milk using classical formulae, such as the VanSlyke formula. These equations are reliable predictors of theoretical or actual yield based on accurately measured milk fat and casein content. Many cheese makers desire to base payment for milk to dairy farmers on the yield of cheese. In small factories, however, accurate measurement of fat and casein content of milk by either chemical methods or infrared milk analysis is too time consuming and expensive. Therefore, an empirical test to predict cheese yield was developed which uses simple equipment (i.e., clinical centrifuge, analytical balance, and forced air oven) to carry out a miniature cheese making, followed by a gravimetric measurement of dry weight yield. A linear regression of calculated theoretical versus dry weight yields for milks of known fat and casein content was calculated. A regression equation of $\mathrm{y}=1.275 \mathrm{x}+1.528$, where $\mathrm{y}$ is theoretical yield and $\mathrm{x}$ is measured dry solids yield $\left(\mathrm{r}^{2}\right.$ $=0.981$ ), for Cheddar cheese was developed using milks with a range of theoretical yield from 7 to $11.8 \%$. The standard deviation of the difference (SDD) between theoretical cheese yield and dry solids yield was 0.194 and the coefficient of variation $(\mathrm{SDD} /$ mean $\times 100)$ was $1.95 \%$ upon cross validation. For cheeses without a well-established theoretical cheese yield equation, the measured dry weight yields could be directly correlated to the observed yields in the factory; this would more accurately reflect the expected yield performance. Payments for milk based on these measurements would more accurately reflect quality and composition of the milk and

\footnotetext{
Received February 2, 2002.

Accepted March 18, 2002.

Corresponding author: D. M. Barbano; e-mail:dmb37@cornell.edu.

${ }^{1}$ Use of names, names of ingredients, and identification of specific models of equipment is for scientific clarity and does not constitute any endorsement of product by authors, Cornell University, the Northeast Dairy Foods Research Center, Consorzio Ricerca Filiera Lattiero Casearia, and Associazione Provinciale Allevatori.
}

the actual average recovery of fat and casein achieved under practical cheese making conditions.

(Key words: Cheese yield prediction, theoretical yield, milk payment method)

\section{INTRODUCTION}

Cheese yield is very economically important (Emmons, 1993a). A cheese maker would like to pay for milk based on the yield of cheese obtained from that milk. The theoretical yield of cheese is limited by the fat and casein (CN) content of the milk used, the ability of the cheese maker to recover the fat and casein as cheese, and the target moisture and salt content. Terms for definition and expression of cheese yield performance have been summarized by Emmons (1993b). Systems for using a theoretical cheese yield formula for pricing milk have been evaluated (Emmons et al., 1990a,b). These pricing systems rely on the measurement of milk fat and milk protein (or $\mathrm{CN}$ ) content to calculate theoretical cheese yield.

Once the cheese maker has purchased the milk, the maximum theoretical cheese yield at a specific moisture and salt content (based on quality considerations) is limited by the concentration of fat and $\mathrm{CN}$ in that milk. Extensive research has been conducted to develop theoretical cheese yield equations that predict yield based on milk composition (i.e., fat and protein or fat and $\mathrm{CN}$ ) for various types of cheeses (Emmons et. al., 1990c, 1993c). One of the first and most common theoretical cheese yield formulas was the VanSlyke formula for Cheddar cheese (VanSlyke and Publow, 1910). The validity and use of theoretical cheese yield formulae for specific types of cheeses, such as Cheddar (Barbano and Rasmussen, 1992; Barbano et al., 1991) and Mozzarella (Rudan, et al., 1999), have been demonstrated in studies of factors influencing cheese yield.

Estimation of the yield potential of milk is needed by both small and large cheese manufacturers. A large industrial manufacturer of cheese may have the financial resources to justify the purchase and maintenance of an infrared milk analyzer to measure milk composi- 
tion and calculate theoretical cheese yield. However, small specialty cheese makers cannot justify this expense. Therefore, a practical and less expensive method of estimation of the yield potential of milk for cheese making could be useful for smaller cheese makers. The goal of this research was to develop an objective method for estimation of cheese yield potential of individual milk samples that could be used as a basis for payment of dairy farmers for cheeses produced from unstandardized milk.

\section{MATERIALS AND METHODS}

\section{General Approach}

The yield prediction method consists of a miniature cheese making followed by a drying step. Milk is added to a pre-weighed centrifuge tube and weighed. Dilute acetic acid is added to reduce the $\mathrm{pH}$ of the milk. The acidified milk is heated to $30^{\circ} \mathrm{C}$ and rennet is added. The coagulated milk is then centrifuged to separate curd from whey. The curd is transferred from the tube to a pre-weighed disposable aluminum total solids weighing dish. The curd is broken with a spatula to provide more surface area for drying and then the curd plus pan is weighed. The curd is dried in a forced air oven. The weight of the curd is determined after drying and divided by the original weight of milk. This produces a value for dry weight yield of cheese.

The method may be calibrated by testing a set of milks that have a range of composition and have established values for fat and protein (or $\mathrm{CN}$ ). The dry weight yield of cheese for these samples is correlated with the calculated theoretical cheese yield to obtain a regression equation for conversion of dry weight yield to theoretical cheese yield. A different regression equation can be computed for each type of cheese produced.

\section{Ruggedness Testing During Method Development}

Many individual parameters were evaluated during the development of the method. A range of sample volumes, type and size of centrifuge tube (plastic or glass), milk temperature at the time of acid addition $\left(4\right.$ to $\left.38^{\circ} \mathrm{C}\right)$, final $\mathrm{pH}$ after acidification (5.6 to 6.6), temperature at rennet addition $\left(30\right.$ to $\left.38^{\circ} \mathrm{C}\right)$, amount $(0.1$ or $0.2 \mathrm{ml})$ of rennet working solution, force of centrifugation, time of centrifugation, and time of oven drying ( 4 to $18 \mathrm{~h}$ ) were evaluated. A final combination of these parameters was selected that optimized the repeatability of the method.

\section{Milk Composition Analysis}

Milk samples collected from eleven individual cows at the Cornell dairy farm were tested for fat content with an infrared milk analyzer (AOAC, 2000; method number 33.2.31; 972.16) CP (AOAC, 2000; method number 33.2.11; 991.20), and noncasein nitrogen (AOAC, 2000; method number 33.2.64; 998.05) content. Casein was calculated by difference between $\mathrm{CP}$ and noncasein nitrogen $\times 6.38$. Each milk sample was tested for SCC using a Fossomatic cell counter (AOAC, 2000; method number 17.13.01; 978.26). Analyses were conducted in duplicate.

\section{Miniature Cheese Making Method}

Routine analysis procedure. Milk at $4{ }^{\circ} \mathrm{C}$ was mixed by inversion and $10 \mathrm{ml}$ was added to a pre-weighed round bottom centrifuge tube (model number 3110-0150, Nalgene Centrifuge Ware, polypropylene copolymer, 15 $\mathrm{ml}, 15.9 \times 113.9 \mathrm{~mm}$ ) and weighed to 4 decimal places. A working solution of acetic acid was prepared by adding $0.9 \mathrm{ml}$ of glacial acetic acid to a $10 \mathrm{ml}$ Class A volumetric flask and diluting to volume with $20^{\circ} \mathrm{C}$ distilled water. For a group of samples that was tested as a batch, 0.1 $\mathrm{ml}$ of diluted acetic acid was added to each tube with a $100 \mu \mathrm{l}$ micropipette. The tubes were covered with parafilm and mixed on a vortex mixer for $15 \mathrm{~s}$. This brought the $\mathrm{pH}$ of the milk to approximately 5.9 at $4^{\circ} \mathrm{C}$. In the routine method, the addition of acetic acid solution is a fixed volume for all samples. The acid was added to achieve a rapid, consistent, and firm coagulation in each milk sample. After adding acid to all tubes, the tubes were placed into a $30^{\circ} \mathrm{C}$ water bath and incubated for $10 \mathrm{~min}$.

While the tubes were incubating, the chymosin working solution was prepared. The chymosin (Chy-Max Extra, Product No. 73863, Chr. Hansens Laboratory, Milwaukee, WI) working solution was made by diluting 1.0 $\mathrm{ml}$ of Chy-Max Extra with distilled water in a $100 \mathrm{ml}$ volumetric flask. A stopper was placed on the flask and the solution was mixed by inversion. The working solution was used immediately; it should not be stored. If the solution was more than $1 \mathrm{~h}$ old, it was discarded and fresh solution was made. Chymosin working solution $(0.1 \mathrm{ml})$ was added to each tube containing the milk plus acid mixture using a $100 \mu \mathrm{l}$ micropipette. Each tube was covered with parafilm, mixed on a vortex mixer for 15 $\mathrm{s}$, and incubated in a water bath at $30^{\circ} \mathrm{C}$ for $30 \mathrm{~min}$. At the end of $30 \mathrm{~min}$, all samples formed a firm coagulum. The maximum number of tubes done in one batch should be equal to the maximum number of individual tubes that can be centrifuged in one batch. The centrifuge tubes were removed from the water bath, the parafilm cover was removed, and they were placed into a centrifuge (Clinical Model, International Equipment Company, Needham Heights, MA). All tubes were centrifuged at setting $7(1,625 \times \mathrm{g})$ for $30 \mathrm{~min}$. After $30 \mathrm{~min}$, 
the tubes were carefully removed from the centrifuge. There was a curd pellet and a clear whey supernatant. The whey from each centrifuge tube was decanted from the pellet left in the bottom of the tube. The sides of the tube were free of curd, and the decanted whey was clear and particulate free. Ideally the whey will have a low fat content (0.04 to $0.06 \%$ ) for all samples and will contain an amount of protein that reflects the normal loss of soluble protein in cheese whey. A predried and cooled disposable aluminum weighing dish was weighed and, using a metal spatula, the curd pellet from the centrifuge tube was quantitatively transferred into the pan. Using two spatulas, the curd in the pan was cut and spread in order to expose more surface area for better drying. All the curd was left in the pan by scraping the spatulas against one another. Two empty predried pans were weighed as blanks. The pans were placed in a forced air drying oven (Stable-Therm OV490A, BlueM Electric, Blue Island, IL) at $100^{\circ} \mathrm{C}$ for $4 \mathrm{~h}$. After $4 \mathrm{~h}$, the pans were removed from the oven, cooled in a desiccator to room temperature, and weighed to 4 decimal places. The dry weight yield was calculated by dividing the weight of dry solids in the aluminum weighing dish, minus the blank, by the original weight of milk in the centrifuge tube and multiplying by 100 .

$$
\begin{aligned}
\text { Dry weight } & \\
\text { yield }= & ((\mathrm{DC}-\text { Blank }) / \mathrm{M}) \times 100, \text { where } \\
\mathrm{DC}= & \text { weight of the dried curd }(\mathrm{g}) \\
\text { Blank }= & \text { weight gain or loss for the blank }(\mathrm{g}), \\
& \text { and } \\
\mathrm{M}= & \text { weight in grams of the milk }(\mathrm{g}) .
\end{aligned}
$$

Calibration. The method was calibrated by conducting the routine test on a group of reference milk samples that had known fat and CN (or protein) contents. The set of calibration samples should have a wide range of fat and CN content to establish a calibration curve over a wide range of cheese yield. A set of commercial raw milk samples typically produced and used for calibration of infrared milk analyzers were a suitable source of samples. For Cheddar cheese, the theoretical cheese yield for each sample was calculated using the VanSlyke formula (VanSlyke and Publow, 1910):

$$
\begin{aligned}
\text { Theoretical } & \\
\text { cheese yield }= & ((\mathrm{FR} \times \mathrm{F})+(\mathrm{CN}-0.1)) \times 1.09 /(1- \\
& (\text { cheese moisture/100) }), \text { where } \\
\mathrm{FR}= & \text { percent fat recovery }(\text { value of } 0.93 \\
& \text { used based on VanSlyke and Publow, } \\
& 1910), \\
\mathrm{F}= & \text { percentage of fat in milk, } \\
\mathrm{CN}= & \text { percentage } \mathrm{CN} \text { in the milk, } \\
0.1= & \text { assumed fixed loss of casein during }
\end{aligned}
$$

Table 1. Somatic cell count, fat, crude protein, noncasein nitrogen, and casein as a percentage of crude protein for calibration milk samples.

\begin{tabular}{lclllll}
\hline Milk sample & $\begin{array}{l}\mathrm{SCC} \\
(\times 1000) / \mathrm{ml}\end{array}$ & $\begin{array}{l}\text { Fat } \\
(\%)\end{array}$ & $\begin{array}{l}\mathrm{CP}^{1} \\
(\%)\end{array}$ & $\begin{array}{l}\mathrm{NCN}^{2} \\
(\%)\end{array}$ & $\begin{array}{l}\mathrm{CN} \\
(\%)\end{array}$ & $\begin{array}{l}\mathrm{CN} / \mathrm{CP}^{3} \\
(\%)\end{array}$ \\
\hline 1 & 74 & 3.86 & 2.63 & 0.57 & 2.06 & 78.3 \\
2 & 22 & 3.86 & 2.74 & 0.54 & 2.20 & 80.3 \\
3 & 28 & 3.44 & 2.56 & 0.67 & 1.89 & 73.8 \\
4 & 11 & 2.36 & 2.63 & 0.69 & 1.94 & 73.8 \\
5 & 316 & 3.80 & 2.99 & 0.72 & 2.27 & 75.9 \\
6 & 29 & 4.48 & 3.44 & 0.67 & 2.77 & 80.5 \\
7 & 1273 & 4.40 & 3.31 & 0.86 & 2.45 & 74.0 \\
8 & 62 & 3.58 & 2.76 & 0.71 & 2.05 & 74.3 \\
9 & 63 & 4.12 & 3.50 & 0.85 & 2.65 & 75.7 \\
10 & 44 & 4.47 & 3.22 & 0.75 & 2.47 & 76.7 \\
11 & 304 & 3.71 & 3.04 & 0.71 & 2.33 & 76.6 \\
Mean & 202 & 3.825 & 2.984 & 0.704 & 2.280 & 76.4 \\
SD & 371 & 0.603 & 0.343 & 0.098 & 0.286 & 2.5 \\
\hline
\end{tabular}

${ }^{1} \mathrm{CP}=$ crude protein.

${ }^{2} \mathrm{NCN}=$ noncasein nitrogen $\times 6.38$.

${ }^{3} \mathrm{CN} / \mathrm{CP}=$ casein as a percentage of crude protein.

the cheese making process,

$1.09=$ factor in the theoretical yield formula assumes a $1.7 \%$ salt content in the cheese, and

cheese

moisture $=$ desired cheese moisture content of $37 \%$.

For other cheese types, the theoretical cheese yield can be calculated using an appropriate formula specific to that cheese type. The calibration was done by calculating a nonzero forcing least squares linear regression of theoretical cheese yield $(\mathrm{Y})$ versus dry weight yield $(\mathrm{X})$ for calibration samples. The linear regression equation derived from the data on the calibration samples was used to convert the dry weight yields from the routine empirical method, when testing unknown samples, to predicted cheese yield.

\section{RESULTS}

\section{Repeatability of the Yield Method}

The composition of the fresh milk samples used for calibration of the empirical cheese yield prediction method is shown in Table 1 . The samples contained a wide range of fat and $\mathrm{CN}$ contents and would be expected to produce a wide range of cheese yields. The $\mathrm{CN}$ as a percentage of CP varied from 73.8 to $80.5 \%$. The SCC of most milks was low (i.e., $<100,000$ cells per $\mathrm{ml}$ ). Three milk samples had a SCC greater than 100,000 cell per $\mathrm{ml}$. In this small group of samples there was no significant correlation between milk SCC and CN as a percentage of CP. The variation from sample to sample in casein as percentage of $\mathrm{CP}$ (i.e., cow to cow) may have been 
Table 2. Percent dry weight, theoretical, and predicted cheese yields for the 11 calibration samples when all samples are used in the regression analysis.

\begin{tabular}{|c|c|c|c|c|}
\hline Milk sample & $\begin{array}{l}\text { Dry weight } \\
\text { yield }\end{array}$ & $\begin{array}{l}\text { Theoretical } \\
\text { yield }\end{array}$ & $\begin{array}{l}\text { Predicted } \\
\text { yield }\end{array}$ & $\begin{array}{l}\text { Predicted minus } \\
\text { theoretical yield }\end{array}$ \\
\hline 1 & 6.433 & 9.604 & 9.729 & 0.125 \\
\hline 1 & 6.369 & 9.604 & 9.647 & 0.043 \\
\hline 1 & 6.387 & 9.604 & 9.670 & 0.066 \\
\hline 2 & 6.373 & 9.841 & 9.652 & -0.189 \\
\hline 2 & 6.357 & 9.841 & 9.632 & -0.209 \\
\hline 2 & 6.363 & 9.841 & 9.639 & -0.202 \\
\hline 3 & 5.666 & 8.618 & 8.751 & 0.133 \\
\hline 3 & 5.671 & 8.618 & 8.757 & 0.139 \\
\hline 3 & 5.695 & 8.618 & 8.788 & 0.170 \\
\hline 4 & 3.980 & 6.978 & 6.602 & -0.376 \\
\hline 4 & 4.534 & 6.978 & 7.308 & 0.330 \\
\hline 4 & 4.519 & 6.978 & 7.289 & 0.311 \\
\hline 5 & 6.614 & 9.871 & 9.959 & 0.088 \\
\hline 5 & 6.641 & 9.871 & 9.994 & 0.123 \\
\hline 5 & 6.636 & 9.871 & 9.987 & 0.116 \\
\hline 6 & 8.304 & 11.822 & 12.114 & 0.291 \\
\hline 6 & 8.271 & 11.822 & 12.072 & 0.249 \\
\hline 6 & 8.246 & 11.822 & 12.040 & 0.217 \\
\hline 6 & 8.224 & 11.822 & 12.012 & 0.189 \\
\hline 7 & 7.531 & 11.154 & 11.128 & -0.026 \\
\hline 7 & 7.649 & 11.154 & 11.279 & 0.125 \\
\hline 7 & 7.570 & 11.154 & 11.178 & 0.024 \\
\hline 7 & 7.651 & 11.154 & 11.281 & 0.127 \\
\hline 8 & 6.047 & 9.139 & 9.237 & 0.098 \\
\hline 8 & 5.992 & 9.139 & 9.167 & 0.028 \\
\hline 8 & 5.963 & 9.139 & 9.130 & -0.009 \\
\hline 8 & 6.013 & 9.139 & 9.193 & 0.055 \\
\hline 9 & 7.327 & 11.052 & 10.868 & -0.183 \\
\hline 9 & 7.308 & 11.052 & 10.844 & -0.207 \\
\hline 9 & 7.349 & 11.052 & 10.896 & -0.155 \\
\hline 9 & 7.312 & 11.052 & 10.849 & -0.202 \\
\hline 10 & 7.616 & 11.293 & 11.237 & -0.056 \\
\hline 10 & 7.567 & 11.293 & 11.174 & -0.118 \\
\hline 10 & 7.423 & 11.293 & 10.991 & -0.302 \\
\hline 10 & 7.431 & 11.293 & 11.001 & -0.292 \\
\hline 11 & 6.397 & 9.822 & 9.683 & -0.139 \\
\hline 11 & 6.397 & 9.822 & 9.683 & -0.139 \\
\hline 11 & 6.413 & 9.822 & 9.703 & -0.119 \\
\hline 11 & 6.410 & 9.822 & 9.699 & -0.123 \\
\hline Mean & & 10.048 & 10.048 & 0.000 \\
\hline SDD & & & & 0.183 \\
\hline SDD/Mean*100 & & & & 1.820 \\
\hline
\end{tabular}

influenced by the age of cow, stage of lactation, and health history (Barbano et al., 1991).

Dry weight yields measured using the miniature cheese making method and the theoretical yields calculated with the VanSlyke yield formula are shown in Table 2 for individual replicates of each of 11 different milk samples. The average theoretical Cheddar cheese yield for these samples was $10.048 \%$. A regression of theoretical yield (Y) as a function of dry weight yield (X), shown in Figure 1, had an equation of $\mathrm{Y}=1.275 \mathrm{X}+$ 1.528 , and $\mathrm{r}^{2}=0.981$. The average repeatability of replications of the same sample for dry weight yield was 0.046 . The standard deviation of the differences between the theoretical yield and predicted yield was 0.183 , and the coefficient of variation (SDD/mean $\times 100$ ) was $1.82 \%$ for 11 milks.
A cross-validation calculation was performed with the data from the 11 individual samples. All possible combinations of ten samples were used as calibration samples, and the regression equations produced from those 11 sets of 10 samples were used to predict the yield for the eleventh sample. The resulting predicted yields by crossvalidation for each of the 11 samples are shown in Table 3 .

\section{DISCUSSION}

In the example shown in this paper, a set of calibration milk samples with known fat and $\mathrm{CN}$ contents were used to predict theoretical Cheddar cheese yield. Using the same data, a calibration curve for predicting cheese yield could be made for any cheese. When constructing the 


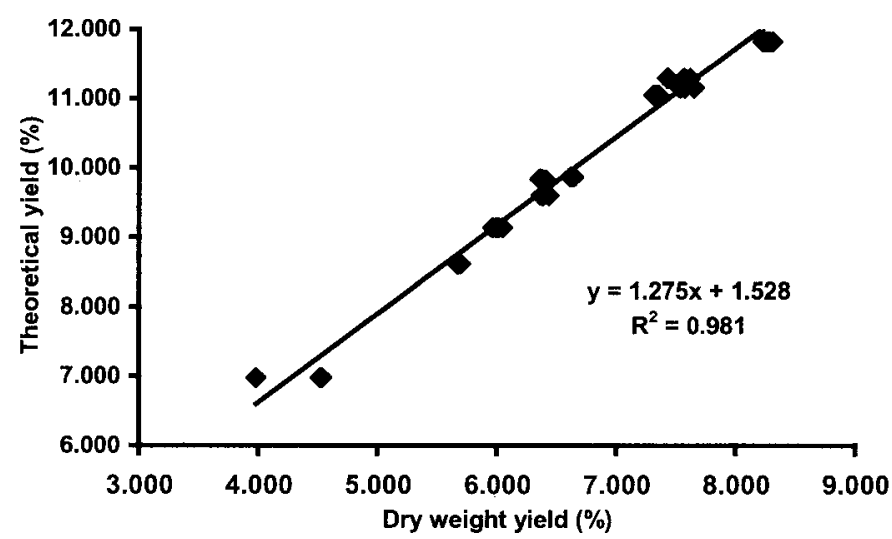

Figure 1. Calibration regression equation for 11 calibration sample set for prediction of theoretical cheese yield using the miniature cheesemaking method.

calibration curve, $\mathrm{CN}$ can either be directly measured (AOAC, 2000; method number 33.2.66; 998.07) or assumed to be a constant proportion of crude or true protein. When $\mathrm{CN}$ is actually measured, the calibration will not be influenced by variation from sample to sample in the $\mathrm{CN}$ as a percentage of $\mathrm{CP}$. If a crude or true protein test of the calibration milks is used and multiplied by a constant conversion factor to estimate $\mathrm{CN}$ content of each calibration milk sample, then variation from sample to sample in $\mathrm{CN}$ as a percentage of $\mathrm{CP}$ will produce a calibration with a higher SDD. The data in Table 2 were recalculated by estimating $\mathrm{CN}$ content $(0.78 \times \mathrm{CP})$, instead of the measured $\mathrm{CN}$ values. When this was done the SDD between theoretical and predicted yield increased from 0.183 to 0.214 . For example, milk \#7 had a high SCC and low CN as a percentage of CP (Table 1). When the measured $\mathrm{CN}$ content of milk 7 was used for the calculation of theoretical yield, the result was 11.154 (Table 3). In cross-validation with a calibration based on measured $\mathrm{CN}$ content, the predicted value for milk 7 was 11.24, and the theoretical yield was 11.154. Thus, the yield prediction method overestimated the yield of this sample by 0.086 . If a constant $\mathrm{CN}$ as a percentage of CP would be used to calculate the theoretical yield of milk 7 , the value would be 11.37 , which is substantially higher than when measured CN content is used. As a result, the difference between theoretical yield and predicted yield would be even larger on this sample when a constant value for $\mathrm{CN}$ as a percentage of $\mathrm{CP}$ is used to estimate $\mathrm{CN}$ content. Thus, the more variation in $\mathrm{CN}$ as a percentage of $\mathrm{CP}$ from sample to sample, the larger the SDD between theoretical and predicted yields. Typically, milk with high SCC and milk produced by older cows with a history of mastitis problems will have low $\mathrm{CN}$ as a percentage of $\mathrm{CP}$ (Barbano et al., 1991).

Another limiting factor is the availability of a theoretical cheese yield equation for each type of cheese. Theoretical yield equations are available for some major varieties of cheese [Cheddar (VanSlyke and Publow, 1910) and Mozzarella (Barbano, 1996)], and general equations (Emmons and LaCroix, 2000) can be applied to many other cheeses. Once a calibration equation is established within a cheese factory, there should not be a need for additional calibration unless there is a major change in the analytical conditions. The validity of the predictive equation can be monitored on a daily basis by testing a sample of milk used for cheese making, calculating the predicted yield, and then comparing the predicted yield to either the actual yield or a moisture adjusted cheese yield (Lau et al., 1990). The moisture adjustment of the

Table 3. Cross validation predictions of yield for each of 11 unknown milk samples when the other 10 milk samples were used as the calibration set.

\begin{tabular}{|c|c|c|c|c|c|c|c|}
\hline Calibration set & $\begin{array}{l}\text { Unknown } \\
\text { sample ID }\end{array}$ & $\begin{array}{l}\text { Dry } \\
\text { weight } \\
\text { yield }\end{array}$ & $\begin{array}{l}\text { Theoretical } \\
\text { yield }\end{array}$ & $\begin{array}{l}\text { Predicted } \\
\text { yield }\end{array}$ & $\begin{array}{l}\text { Predicted } \\
\text { minus } \\
\text { theoretical }\end{array}$ & Regression equation & $\mathrm{R}^{2}$ \\
\hline 1 & 1 & 6.396 & 9.604 & 9.682 & 0.078 & $Y=1.2869 x+1.4504$ & 0.988 \\
\hline 2 & 2 & 6.364 & 9.841 & 9.611 & -0.230 & $\mathrm{Y}=1.2927 \mathrm{x}+1.3839$ & 0.990 \\
\hline 3 & 3 & 5.677 & 8.618 & 8.773 & 0.155 & $Y=1.2758 x+1.5301$ & 0.988 \\
\hline 4 & 4 & 4.344 & 6.978 & 7.090 & 0.112 & $Y=1.2663 x+1.5892$ & 0.977 \\
\hline 5 & 5 & 6.630 & 9.871 & 9.987 & 0.116 & $Y=1.2886 x+1.4427$ & 0.989 \\
\hline 6 & 6 & 8.261 & 11.822 & 12.202 & 0.380 & $\mathrm{Y}=1.3431 \mathrm{x}+1.1068$ & 0.991 \\
\hline 7 & 7 & 7.600 & 11.154 & 11.240 & 0.086 & $\mathrm{Y}=1.2957 \mathrm{x}+1.3928$ & 0.987 \\
\hline 8 & 8 & 6.004 & 9.139 & 9.173 & 0.034 & $\mathrm{Y}=1.2864 \mathrm{x}+1.4493$ & 0.988 \\
\hline 9 & 9 & 7.324 & 11.052 & 10.840 & -0.211 & $Y=1.2748 x+1.5038$ & 0.989 \\
\hline 10 & 10 & 7.509 & 11.293 & 11.071 & -0.221 & $Y=1.2706 x+1.5304$ & 0.989 \\
\hline 11 & 11 & 6.404 & 9.822 & 9.670 & -0.152 & $Y=1.2907 x+1.4045$ & 0.989 \\
\hline Mean & & 6.592 & 9.927 & 9.940 & 0.013 & & \\
\hline $\mathrm{SDD}^{1}$ & & & & & 0.194 & & \\
\hline SDD/mean*100 & & & & & 1.954 & & \\
\hline
\end{tabular}

${ }^{1} \mathrm{SDD}=$ standard deviation of the difference between theoretical cheese yield and predicted yield. 
actual yield would use the same target moisture value used in the theoretical yield formula.

However, even this degree of sophistication is not absolutely necessary in a small specialty cheese factory with limited resources. The proposed method can be applied in other ways. The dry weight yield measured using the miniature cheese making method could be determined each day on a sample of the milk used for cheese making in the factory. The actual wet and dry weight yields of cheese in the factory for each day of cheese making could be determined by weighing the cheese and measuring the moisture content. With a simple linear regression performed in a spreadsheet program, a prediction equation could be produced that is specific for the cheese type and manufacturing conditions in that factory. This would provide a prediction of cheese yield that would reflect the expected performance of the cheese making and the average milk quality in that factory and could be used as a basis for milk payment. This miniature cheese making method and the equation could be applied to milks from individual farms to estimate the yield of cheese that the factory would obtain from that milk.

\section{CONCLUSIONS}

Correlations between dry weight yield determined using the new method and theoretical cheese yield prediction using the VanSlyke yield formula were very high. The cheese yield prediction method uses equipment (clinical centrifuge, electronic balance, and a forced air drying oven) that costs less and is less complicated to operate than chemical or infrared milk analysis equipment. The balance and drying oven could also be used to determine the moisture content of the cheese in the factory, and small specialty cheese factories may already have this equipment. For cheeses without a well established theoretical cheese yield equation, the measured dry weight yields could be directly correlated to the observed yields in the factory. This would more accurately reflect the expected yield for that factory. Milk purchases based on these measurements would more accurately reflect the quality and composition of the milk and the actual average recovery of fat and $\mathrm{CN}$ achieved in the cheesemaking factory.

\section{REFERENCES}

Association of Official Analytical Chemists International. 2000. 17th Edition. Official Methods of Analysis. AOAC International, Gaithersburg, Maryland.

Barbano, D. M. 1996. Mozzarella cheese yield: factors to consider. Pages 29-38 in Proceedings of the seminar on Maximizing Cheese Yield. Center Dairy Res., University of Wisconsin, Madison.

Barbano, D. M., and R. R. Rasmussen. 1992. Cheese yield performance of fermentation-produced chymosin and other milk coagulants. J. Dairy Sci. 75:1-12.

Barbano, D. M., R. R. Rasmussen, and J. M. Lynch. 1991. Influence of milk somatic cell count and milk age on cheese yield. J. Dairy Sci. 74:369-388.

Emmons, D. B. 1993a. Economic importance of cheese yield. Pages 10-11 in Factors Affecting the Yield of Cheese. Int. Dairy Fed. Special Issue No. 9301, Brussels.

Emmons, D. B. 1993b. Definition and expression of cheese yield. Pages 12-20 in Factors Affecting the Yield of Cheese. Int. Dairy Fed. Special Issue No. 9301, Brussels.

Emmons, D. B., C. A. Ernstrom, C. A. Lacroix, and P. Verret. 1990c. Predictive formulas for yield of cheese from composition of milk: a review. J. Dairy Sci. 73:1365-1394.

Emmons, D. B., C. A. Ernstrom, C. A. Lacroix, and P. Verret. 1993c. Yield formulae. Pages 21-48 in Factors Affecting the Yield of Cheese. Int. Dairy Fed. Special Issue No. 9301. Brussels.

Emmons, D. B., and C. Lacroix. 2000. Use of predictive yield formulae. Pages 60 to 73 in Practical Guide for Control of Cheese Yield. Int. Dairy Fed., Brussels.

Emmons, D. B., D. Tulloch, and C. A. Ernstrom. 1990a. Product-yield pricing system. 1. Technological considerations in multiple component pricing of milk. J. Dairy Sci. 73:1712-1723.

Emmons, D. B., D. Tulloch, C. A. Ernstrom, M. Morisset, and D. Barbano. 1990b. Product yield pricing system. 2. Plant considerations in multiple-component pricing of milk. J. Dairy Sci. 73:1724-1733.

Lau, K. Y., D. M. Barbano, and R. R. Rasmussen. 1990. Influence of pasteurization on fat and nitrogen recoveries and Cheddar cheese yield. J. Dairy Sci. 73:561-570.

Rudan, M. A., J. J. Yun, D. M. Barbano, P. S. Kindstedt, and K. L. Larose. 1999. Mozzarella cheese: effect of fat reduction on composition, proteolysis, functionality, and yield of Mozzarella cheese. J. Dairy Sci. 82:661-672.

VanSlyke, L. L., and C. A. Publow. 1910. The Science and Practice of Cheese Making. Orange Judd Company, New York. 